\title{
Water for the Twenty First Century, Can Small Solutions Help Tackle One of the Biggest Problems Facing Humanity?
}

\author{
Anas Ghadouani \\ Professor of Environmental Engineering \\ The University of Western Australia
}

Are we ready for a radical change in the way we approach the daunting problem of water shortage or "water access"? For decades now, we have deployed enormous resources globally to try to address some alarming figures around lack of access to safe water and sanitation, especially in the developing world. It is safe to say that the picture globally isn't one of huge success; while we have recorded many successes, the world still witnesses 800 child deaths per day or 1 child death every 2 minutes. I will argue that our failures are caused by the focus on major capital investment and mega-project that are inherently costly, and where the core of the funding is spent on project/program management. Are we ready to review this approach by adopting local solutions that are well integrated with the local infrastructure, and more importantly with the socio-economic fabric? How could engineers lead the way in forming multidisciplinary teams with the aim of providing new and flexible solutions to water issues around the world? Innovative technologies are critical to ensuring future challenges are addressed, but to maximise the benefit and the uptake of the technologies we need to work on developing a deeper understanding of the local characteristics of the problem and tailor the solutions accordingly. Examples drawn from around the world will be used to illustrate the need for a multidisciplinary approach focused on localised and flexible solutions to solving water problems. 